\title{
Extended training and multiple shifts: Percentage of reward
}

\author{
GARVIN MCCAIN, MICHAELLOBB, and JAMES NEWBERRY \\ University of Tesoas, Arlingtom, Texas 76019
}

\begin{abstract}
This is one paper of a series investigating the effects of extended training and multiple successive reward shifts. Four groups were run in a straight alley. The control groups received either $75 \%$ or $25 \%$ reinforcement throughout training. Each experimental group was given 40 acquisition trials at either $75 \%$ or $25 \%$ reinforcement followed by three shifts of 24 trials each. All groups were given 24 extinction trials. There were initial significant differences between the $75 \%$ and $25 \%$ groups. These differences disappeared after about 40 trials. The only significant shift effect was a NCE on the third shift. Extinction results were a function of the initial acquisition series. Together with earlier studies, these results indicate that extended training effects are often different from early stages of training.
\end{abstract}

This is another paper from a series of studies examining the effects of different reinforcement parameters over extended training (McCain, 1970; McCain \& Cooney, 1975; McCain, Dyleski \& McElvain, 1971; McCain, Lobb, Almand \& Leck, in press; McCain, Ward, \& Lobb, 1976).

The earliest studies from this laboratory and others involved different magnitudes of consistent reward. There now exists a very substantial body of evidence indicating that under these conditions any initial acquisition differences due to reward magnitude disappear after extended training (e.g., Black, 1969; Campbell, Batsche, \& Batsche, 1972; McCain, 1970; McCain et al., 1971; McCain et al., 1976; Shanab, France, \& Young, 1976). Similar effects were seen when different magnitudes of 50\% reward were given (Capaldi \& Freese, 1974; McCain, 1970; Meyers \& Anderson, 1975). Recently, comparisons of delay of reinforcement (10 vs. $30 \mathrm{sec}$ ) have yielded the same sort of results (McCain et al., in press). In addition to the long-term acquisition effects, multiple shifts of consistent reward have given a clear PCE (Benefield, Oscós, \& Ehrenfreund, 1974; McCain \& Cooney, 1975; Shanab et al, 1976). In each of these studies, shifts from large to small to large reward gave a clear PCE on the shift back to large reward. In the delay study (McCain et al., in press), multiple shifts gave only a large NCE. Extinction has also been shown to be different depending on the level of training and prior shifting (e. g., Capaldi \& Freese, 1974; McCain, 1970; McCain et al., 1971; McCain \& Cooney, 1975; Meyers \& Anderson, 1975). In summary, where a variety of dimensions and measures of the effects of reward have been examined there have been substantial differences between results early in training and those found after extended training.

The objective in the present study was, first, to

This research was supported by a grant from the Organized Research Fund, University of Texas at Arlington. Thanks are due to Paula Goodman and Greg Watson, who ran the subjects. examine long-term acquisition effects of different percentages of reward and, second, to assess the effects of multiple shifts of reward percentage. Weinstock's (1958) early and very important study on acquisition and extinction with various percentages of reward $(17 \%, 33 \%, 50 \%, 67 \%, 83 \%$, and $100 \%)$ indicated that late in training the groups $17 \%-67 \%$ ran at about the same speed. The $83 \%$ group was somewhat slower than these groups; the $100 \%$ group was slowest of all. Although Weinstock states that "The two groups receiving the smallest proportions of reward ran most slowly for the first two blocks of six trials," he did not present a detailed analysis of group differences. In terms of the present line of research, the Weinstock study may not be directly comparable, since he preceded all reinforcement schedules with 12 consistently reinforced trials.

\section{METHOD}

\section{Subjects and Apparatus}

The subjects were 44 Holtzman rats, approximately 90 days old when received. Five subjects were lost due to illness; their scores are not included in any analysis. The straight alley was approximately $160 \mathrm{~cm}$ long. Timing was over the first $76 \mathrm{~cm}$ and last $30.5 \mathrm{~cm}$ of the alley. A more complete description may be found in McCain and Cooney (1975).

\section{Procedure}

The subjects were maintained on an ad-lib diet for 5 days after receipt. During the preexperimental phase and throughout the study, they were maintained on a 13-g daily diet. Food received in the alley was deducted from cage feeding. Beginning on the first day of deprivation, subjects were handled individually for $2 \mathrm{~min} / \mathrm{day}$. After 6 days of handling, subjects were given 4 days of exploration at $3 \mathrm{~min} / \mathrm{day}$ in the unbaited alley. All equipment was turned on for the exploration period. The alley was swabbed with Pine-Sol after each individual exploration period. Two groups were formed on a random basis. One group was given $75 \%$ reward over each eight-trial block, the other, $25 \%$ reward. Goalbox confinement was $20 \mathrm{sec}$ on nonreinforced trials. All subjects were given four trials per day for the first 2 days and eight trials per day throughout the remainder of the study. The intertrial interval was $10 \mathrm{sec}$ throughout the study. After 40 acquisition trials, each initial group was divided on a 


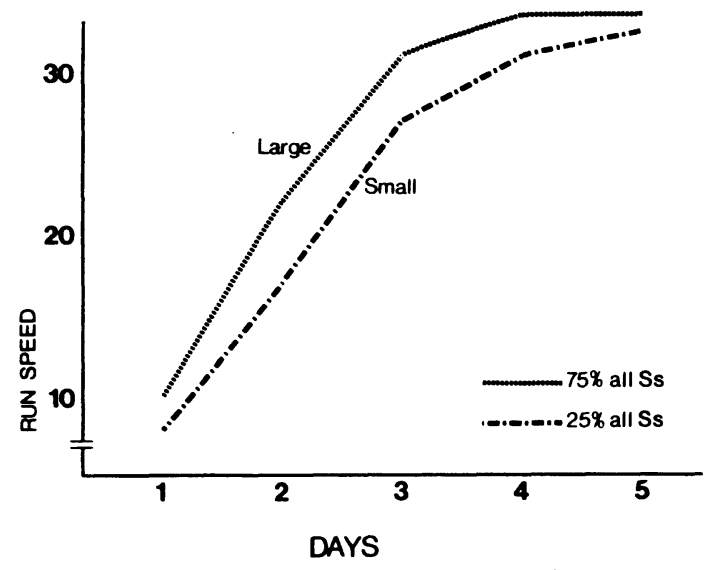

Figure 1. Transformed run speeds $[\log 1 / \operatorname{med}+1)]$ for acquisition prior to the first shift.

random basis to produce a total of four groups: (a) a $75 \%$ control group (LLLL); (b) a $25 \%$ control group (SSSS); (c) a group shifted to $25 \%, 75 \%, 25 \%$ (LSLS); (d) a group shifted to $75 \%, 25 \%, 75 \%$ (SLSL). Each shift consisted of 24 trials. All subjects were given 24 extinction trials with $20 \mathrm{sec}$ goalbox confinement on each trial. Subjects failing to reach the goalbox within 1 min during acquisition or extinction were guided to the goalbox and given a run time of $45 \mathrm{sec}$ and a goal time of $15 \mathrm{sec}$.

\section{RESULTS}

Run times were transformed to a speed measure $[R S=\log 10(1 / \mathrm{med}+1)]$. The goal speeds were compatible with the RS analysis and will not be presented here. As may be seen in Figure 1,75\% reward produced faster running in the early stages of training. A comparison over the first 4 days of acquisition indicates the $75 \%$ group was significantly faster than the $25 \%$ group $(F=6.90, \mathrm{df}=1 / 39, \mathrm{p}<.025)$. On the 5 th day the groups are within a rounding error of each other. Figure 2 shows that Groups LLLL and SSSS were very similar over Days 9-14. Their overall means for these 6 days were within a rounding error of each other. The three shifts are shown in Figure 2. There was no PCE on any of the three shifts. The only significant NCE occurred on the third shift. Here there was a significant Groups by Days interaction between Groups SSSS and LSLS (F = 3.56, df $=2 / 35, \mathrm{p}<.05)$. These groups did differ significantly on Day 12 $(\mathrm{t}=3.20, \mathrm{df}=17, \mathrm{p}<.01)$. There was a significant experimenter effect in this shift, but the significance levels reported above do not change substantially whether or not the experimenter effect is factored out. In Shift 1, when Group LSLS was shifted to $25 \%$ they ran slightly faster over days, although the difference was not significant. In extinction there was a significant Groups effect $(F=4.79, \mathrm{df}=3 / 35, \mathrm{p}<.01)$. Individual groups were compared using the Scheffé test. Groups SSSS, LSLS, and SLSL were all significantly more resistant to extinction than Group LLLL $(p<.05$ in each case).
Since it appeared that the groups given original acquisition of $75 \%$ were less resistant to extinction and since in an earlier study on consistent reinforcement (McCain \& Cooney, 1975) the terminal reinforcement condition had determined resistance to extinction. groups were compared in a 2 by 2 analysis. The conditions were percentage of reward in initial acquisition and percentage of reward during terminal reinforcement. In initial reinforcement, the main effect comparison was highly significant $(F=10,82, d f=1 / 35, p<.005)$. There were no other significant differences. Figure 3 shows the 3 days of extinction. The rate of extinction for Group LSLS appears to differ from the other groups over days of extinction. However, the Groups by Days interaction was not significant.

\section{DISCUSSION}

In the present study there was very clear evidence of an early performance difference related to percentage of reinforcement,

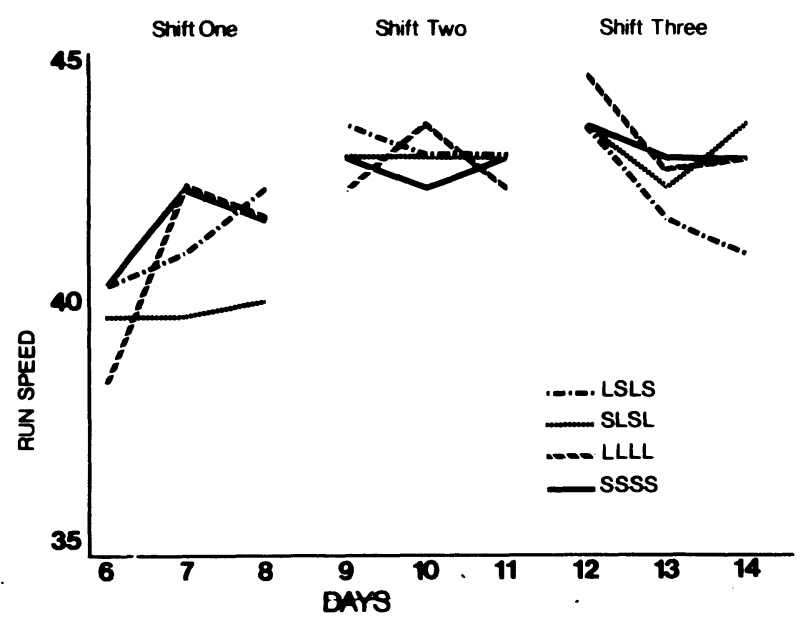

Figure 2. Transformed run speeds $[\log (1 / \mathrm{med}+1)]$ for the three shifts.

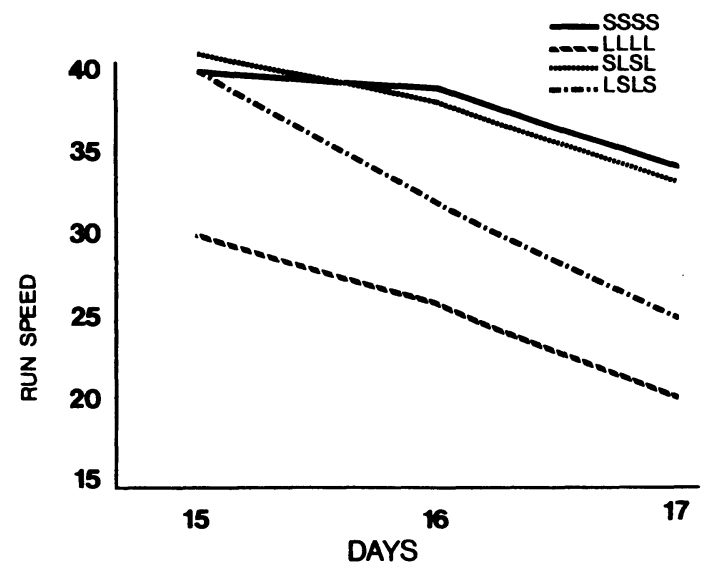

Figure 3. Transformed run speeds $[\log (1 / \mathrm{med}+1)]$ during extinction. 
with these differences disappearing after extended training. This appears quite similar to results cited earlier in the cases of different magnitudes of consistent or partial reward and delay of reinforcement. It should be noted that these studies have covered only a limited range of magnitudes, delays, and percentages of reward. More extreme conditions also need investigation. It is possible that each of these reward-related phenomena will require a separate explanation. More appealing, and certainly more parsimonious, would be a single explanation that covers these separate conditions. No current analysis of reinforcement conditions seems to either explain or predict these separate manipulations which appear to have a functionally similar result. One possible line of explanation would involve the effects of preexperimental feeding. Typical cage feeding seems to resemble larger magnitudes, shorter delays, and higher percentages of reward more than small magnitudes, long delays, and low percentages of reward. Such a situation might well condition an expectancy of reward conditions that would affect the earlier stages of training under different stimulus conditions, such as a straight alley. Later adaptation to a set of specific stimulus conditions might account for the lack of difference late in training. There is no data to support this vague speculation. It may suggest some lines of investigation.

The shift data are somewhat surprising in two ways. First, in Shift 1, when the rats of Group LSLS were shifted to $25 \%$ reward, they ran faster. This certainly does not fit any of our preconceptions as to possible negative contrast effects. Second, this same group, when shifted to $25 \%$ reward on the third shift, did yield an NCE. Investigation of multiple reward shifts has been extremely limited to date. It is not at all clear why successive shifts produce effects that do not appear with single shifts. The main point to be made at this time is that these changes over shifts do occur and the initial shifts do not necessarily predict these effects.

In extinction there is a clear effect related to the original acquisition schedule. These results are quite different from those found when original acquisition and the shifts involved magnitudes of consistent reward. In that situation, McCain and Cooney (1975) found that the terminal reinforcement condition was the best predictor of extinction. None of this makes the situation clear. The safest comment is that, over extended training and over multiple shifts, the results differ from those early in training or in single shifts.

There has been no at tempt to analyze these results in theoretical terms. The data here and from the studies cited are too sparse and too confusing to determine any regular pattern. The one thing that does come through the chaos is that results from extended training and multiple reward shifts are different from those obtained early in training and with single shifts. Theories based on limited training may well require substantial extension and/or revision to explain this fragmentary but emerging empirical base.

\section{REFERENCES}

Benefield, R., Oscós, A., \& Ehrenfreund, D. Role of frustration in successive positive contrast. Joumal of Comparative and Physiological Psychology. 1974, 86, 648-651.

BLACK, R. W. Incentive motivation and the parameters of reward in instrumental conditioning. In W. J. Arnold \& D. Levine (Eds.). Nebraska Symposium on Motivation. Lincoln: University of Nebraska Press, 1969.

Campbell, P. E., Batsche, C. J., \& Batsche, G. M. Spaced trials reward magnitude effects in the rat: Single versus multiple food pellets. Journal of Comparative and Physiological Psychology, 1972, 81, 360-364.

Capaldi, E. J., \& Freese, M. R. Partial reward training level and reward magnitude: Effects on acquisition and extinction. Learning and Motivation, 1974, 5, 299-310.

McCain, G. Reward magnitude and instrumental responses: Consistent and partial reward. Psychonomic Science, 1970, 19, 139-141.

McCain, G., \& Cooney, J. PCE I: The effects of three reward magnitude shifts. Bulletin of the Psychonomic Society, 1975, 6, 523-526.

McCain, G., Dyleski, K., \& McElvain, G. Reward magnitude and instrumental responses: Consistent reward. Psychonomic Monograph Supplements, 1971, 3(Whole No. 48).

McCain, G., Lobb, M., Almand, W., \& Leck, D. Delay of reinforcement: Extended training and multiple shifts, in press.

MCCAIN, G., WARD, R., \& LOBB, M. Reward magnitude and a comment. Bulletin of the Psychonomic Society, 1976, 7, 90-92.

MeYers, L. S., \& Anderson, G. J. Acquisition and extinction following extended partial reinforcement under small or large reward. Bulletin of the Psychonomic Society, 1975, 6, 198-200.

Shanab, M. E., France, J., \& Young, T. Positive and negative contrast effects obtained following shifts in liquid sucrose reward in thirsty rats. Animal Learning \& Behavior, 1976, 4, 9-12.

Weinstock, S. Acquisition and extinction of a partially reinforced running response at a 24-hour intertrial interval. Journal of Experimental Psychology, 1958, 56, 151-158.

(Received for publication May 17, 1976.) 